DOI: 10.12731/2077-1770-2018-4-247-254

УДК 812

\title{
СТРУКТУРА СЛОВООБРАЗОВАТЕЛЬНОГО ГНЕЗДА С ВЕРШИНОЙ «ГУРГЭ»
}

\section{Саввинова С.H.}

Цель. Статья посвящена актуальной теме словообразования в исследовании эвенского языка. Предметом анализа выступают словообразовательные гнезда. Автор ставит целлю раскрыть структуру словообразовательного гнезда с верииной «гургэ» и словообразовательные возможности частей речи в эвенском языке.

Метод или методология проведения работы. Основу исследования образует метод описательно-типологический, который позволил системно охарактеризовать материал. Структура и формальные связи внутри словообразовательного гнезда исследовань при помощи перспективного словообразовательного анализа. В статье также применен статистический анализ.

Результаты. Результаты работы заключаются в определении структуры словообразовательного гнезда с вершиной гургэ «работа» представляет собой совокупность словообразовательных парадигм, рассматриваемых как комплекс производных, имеющих одну и ту же основу и находящихся на одной ступени деривации.

Область применения результатов. Результать исследования могут быть применены при составлении словообразовательного словаря эвенского языка, также могут быть использованы при составлении спецкурсов для студентов по лексикологии и словообразованию.

Ключевые слова: словообразование; словообразовательное гнезда; дериват; парадигма; словообразовательная цеепь; эвенский язык.

\section{STRUCTURE OF THE WORD-BUILDING NEST WITH THE TOP "GURGE"}

\section{Savvinova S.N.}

Purpose. The article is devoted to the topical issue of word formation in the study of the Even language. The subject of analysis is 
the word-building nests. The author aims to reveal the structure of the word-building nest with the top "gurge" and the word-formative capabilities of parts of speech in the Even language.

Methodology. The basis of the study is the descriptive-typological method, which contributed to the system description of the material under study. The structure and formal connections within the word-building nestare investigated using the perspective word-formation analysis. The article also uses the statistical analysis.

Results. The results of the work consist in the fact that the word-building nest with the top gurge ("work") has been defined as a set of word-formation paradigms, which are considered as a set of derivatives having the same basis and being on the same stage of derivation.

Practical implications. The results of the research can be applied to the compilation of the derivational dictionary of the Even language also as well as to compile special courses for students in lexicology and word formation.

Keywords: word formation; word-building nest; derivative; paradigm; word-forming chain; Even language.

Словообразование является одним из важнейших источников как пополнения словарного запаса языка, так и образования новых слов. В настоящее время словообразование - весьма актуальная тема в исследовании языков в целом и языков малочисленных народов Севера, в частности.

Значительное место вопросам словообразования отведено в работах тунгусоведов В.И. Цинциус, К.А. Новиковой, В.А. Роббека, В.Д. Лебедева, А.А. Бурыкина, Б.В. Болдырева, А.Н. Мыреевой и др. В виде научных статей разработаны словообразовательные проблемы Р.П. Кузьминой, Г.В. Роббеком, Е.В. Нестеровой, И.И. Садовниковой, но специальных работ, посвященных словообразованию в эвенском языке, нет, что определяет новизну выбранной темы. Актуальность данной темы определяется отсутствием словообразовательного словаря эвенского языка.

Словообразование эвенского языка определяется его агглютинативным характером, при котором слово образуется способом аффиксации. 
В нашей статье будет рассмотрено словообразовательное гнездо с вершиной гургэ по материалам «Эвенско-русского словаря» [8]. Семантическое значение аффиксов определялось по этому словарю, а также по труду В.И. Цинциус «Очерк грамматики эвенского (ламутского) языка» [11], в котором зафиксированы принципы словообразования и словоизменения и алфавитный перечень всех рассмотренных суффиксов и частиц.

Словообразовательное гнездо с вершиной гургэ1. работа, труд, дело, занятие; 2. рабочий, трудовой имеет 14 производных слов как в парадигматическом, так и в синтагматическом плане. Первая парадигма с исходным словом гургэ 1. работа, труд, дело, занятие; 2. рабочий, трудовой имеет один дериват:

Гургэ - Гургэ/вчи/дэй работать, трудиться

Производное слово в данной парадигме представлено одним глаголом гургэвчидэй, которое образовано аффиксальным способом словообразования: гургэ-вчи-дэй.

Вторая парадигма представлена вершиной Гургэ/вчи/дэйработать, трудитьсяс13 дериватами:

Гургэ/вчи/б/дэй обрабатываться, отделываться

Гургэ/вчи/в/дэй вырабатываться, выделываться

Гургэ/вчи/дек 1) работа, занятие, деятельность; 2) рабочее место

Гургэ/вчи/лдывун орудие труда

Гургэ/вчи/л/дэй приняться за работу, взяться за дело

Гургэ/вчи/мнэ рабочий, работник

Гургэ/вчи/н, гургэвчинмэй работа, занятие, деятельность

Гургэ/вчи/нэ/дэй идти на работу, службу

Гургэ/вчи/ри 1. Работающий, служащий; 2.1) работа, занятие, дело; 2) работник,

Гургэ/вчи/вэт/тэй работать, трудиться

Гургэ/вчи/вкэн/дэй заставить работать, засадить за работу

Гургэ/вчи/вкэт/тэй заставлять работать, усаживать за работу

В данной парадигме производные слова выражены 4 именами существительными и 7 глаголами. Глагольный блок составляют 7 
глагольных форм - 4 залоговых и 3 видовых. Например: залоговые формы:

Гургэ/вчи/б/дэй обрабатываться, отделываться гургэ+вчи (суффикс отыменного глагола + б (суффикс средне-возвратного залога) + дэй.

Форму глагола со значением возвратности именуют по-разному. В «Очерке грамматики ламутского языка» В.И. Цинциус называет «формой средне-возвратного залога» [11, с. 176]. В.А. Роббек пишет, что данная категория образуется при помощи различных формантов, которые «зависимы от лекиско-грамматических групп глаголов и придают глагольной основе дополнительные семантические значения» [7, с. 267], и далее «другие же форманты меняют лексическое значение основы глагола. Поэтому правы исследователи, которые относят их к сфере словообразования (точнее основообразования), подчеркивая отличие от словоизменительного характера суффикса страдательного залога» [Там же, с.268].

Гургэ/вчи/в/дэй вырабатываться, выделываться гургэ+вчи (суффикс отыменного глагола + в (суффикс глагола страдательного залога) +дэй. Гургэ/вчи/вкэн/дэй заставить работать, засадить за работу гургэ+вчи (суффикс отыменного глагола + вкэн (суффикс глагола побудительного залога) +дэй.

Гургэ/вчи/вкэт/тэй заставлять работать, усаживать за работугургэ+вчи (суффикс отыменного глагола)+ вкэт (суффикс глагола побудительного залога) +тэй.

И видовые формы. «Видом эвенского глагола мы называем такую категорию, которая выражается путем преимущественно суффиксального усложнения первичной глагольной основы, вследствие чего новая основа приобретает дополнительные оттенки значения, связанные с представлением о характере протекания действия» [7, с. 357]. Например:

Гургэ/вчи/л/дэй приняться за работу, взяться за делогургэ+вчи (суффикс отыменного глагола)+ л (суффикс глагола начинательного вида)+дэй.

Гургэ/вчи/нэ/дэй идти на работу, службу гургэ+вчи (суффикс отыменного глагола) + нэ (суффикс глагола вида отправления) +дэй. 
Гургэ/вчи/вэт/тэй работать, трудиться гургэ+вчи (суффикс отыменного глагола) + вэт (суффикс глагола обычного вида) +тэй.

Исходя из этого, можно сделать вывод, что видовые формы эвенского глагола тоже участвуют в словообразовании.

Именная часть состоит из 5 производных:

Гургэ/вчи/дек - имя места или процесса: 1) работа, занятие, деятельность; 2) рабочее место

Гургэ/вчи/лдывун - имя орудия: орудие труда

Гургэ/вчи/мнэ - название лица, со значением рода занятия: рабочий, работник

Гургэ/вчи/н - имя определенного действия: работа, занятие, деятельность

Гургэ/вчи/ри суффикс причастия настоящего времени: 1. Работающий, служащий; 2.1) работа, занятие, дело; 2) работник, работница.

Также надо отметить, что в анализируемом словообразовательном гнезде с вершиной гургэ 1) Работа, труд, дело, занятие; 2) Рабочий, трудовой в синтагматическом плане можно выделить 13 словообразовательных цепей. Известно, что словообразовательные цепи делятся на бинарные (исходное слово и одно производное слово) и полинарные (могут быть до несколько дериватов). Словообразовательные цепи в количественном плане состоят из 15 полинарных цепей и одной бинарной, которая равна словообразовательной паре: гургэ-гургэвчидэй.

Таким образом, словообразовательное гнездо с вершиной гургэ работа представляет собой совокупность словообразовательных парадигм, которые рассматриваются как совокупность производных, имеющих одну и ту же основу и находящихся на одной ступени деривации. Анализируемое гнездо имеет две парадигмы, которые находятся на первой ступени деривации.

На синтагматическом уровне данное гнездо с вершиной гургэ является совокупностью словообразовательных цепей.

\section{Список литературы}

1. Болдырев Б.В. Словообразование имен существительных в тунгусоманьчжурских языках в сравнительно-историческом освещении. Новосибирск: Наука, 1987. 208 с. 
2. Кузьмина Р.П. Особенности словообразования эвенского языка (на материале ламунхинского говора эвенского языка) // Вестник Поморского университета. Серия «Гуманитарные и социальные науки». 2011, №8. С. 139-143.

3. Кузьмина Р.П. Диалектное словообразование в эвенских говорах // Материалы XIII международной конференции «Актуальные проблемы диалектологии языков народов России». Уфа, 13-14 сентября 2013 г. С. 68-70.

4. Нестерова Е.В.Образные слова эвенского языка. Новосибирск: Наука, 2010. $111 \mathrm{c}$.

5. Роббек В.А. О некоторых закономерностях сочетания суффиксов в одной глагольной основе эвенского языка // Вопросы языка и фольклора народностей Севера. Якутск, 1980. С. 42-52.

6. Роббек В.А. Виды глагола в эвенском языке. Л.: Наука, 1982. 113 с.

7. Роббек В.А. Грамматические категории эвенского глагола в функционально-семантическом аспекте. Новосибирск: Наука, 2007. $726 \mathrm{c.}$

8. Роббек В.А., Роббек М.Е. Эвенско-русский словарь. Новосибирск: Наука, 2005. 353 с.

9. Садовникова И.И. Лексико-семантическое словообразование как способ обогащения эвенского языка // Актуальные вопросы современного языкознания // Новосибирск, 2012. С. 120-136.

10. Тихонов А.Н. Словообразовательный словарь русского языка: в 2-х т. М.: Русский язык, 1985. Т. 1.856 с. Тихонов А.Н. Словообразовательный словарь русского языка: в 2-х т. М.: Русский язык, 1985. Т. 2. $887 \mathrm{c}$.

11. Цинциус В.И. Очерк грамматики эвенского (ламутского) языка. Ч.1. Л.: Учпедгиз, 1947. 269 с.

12. Wellmann H. Deutsche Wortbildung, Typen und Tendenzen in der Gegenwartsprache. Zweiter Hauptteil: Das Substantiv. Schwann, Düsseldorf, $1975.500 \mathrm{p}$.

13. Dokulil M. Tvorenislov v cestine. T. 1. Praha: CSAV, 1962. 263 p.

14. Arnold I.V. The English Word. M.: BILL, 1986. 296 p.

15. Bloomfield L. Language. New York: Holt, 1979. 564 p. 


\section{References}

1. Boldyrev B.V. Slovoobrazovanie imen sushchestvitel'nykh v tunguso-man'chzhurskikh yazykakh v sravnitel'no-istoricheskom osveshchenii [The Word Formation of Nouns in the Tungus-Manchu Languages in Comparative-Historical Aspect]. Novosibirsk: Nauka, 1987. 208 p.

2. Kuz'mina R.P. Osobennosti slovoobrazovaniya evenskogo yazyka (na materiale lamunkhinskogo govora evenskogo yazyka) [Peculiarities of the Derivation of the Even Language (on the Basis of the Laminkhin Dialect of the Even Language)]. Vestnik Pomorskogo universiteta. Seriya “Gumanitarnye i sotsial'nye nauki”. 2011, №8: 139-143.

3. Kuz'mina R.P. Dialektnoe slovoobrazovanie v evenskikh govorakh [Dialectical Word Formation in Even Dialects]. Materialy XIII mezhdunarodnoy konferentsii "Aktual'nye problemy dialektologii yazykov narodov Rossii" [Materials of the XIII International Conference "Actual Problems of Dialectology of Languages of the Peoples of Russia"]. Ufa, 13-14 sentyabrya 2013 g.: 68-70.

4. Nesterova E.V. Obraznye slova evenskogo yazyka [The Idiomatic Words of the Even Language]. Novosibirsk: Nauka, 2010. 111 p.

5. Robbek V.A. O nekotorykh zakonomernostyakh sochetaniya suffiksov v odnoy glagol'noy osnove evenskogo yazyka [On Certain Regularities of Combination of Suffixes in a Verbal Stem of the Even Language]. Voprosy yazyka i fol'klora narodnostey Severa. Yakutsk, 1980: 42-52.

6. Robbek V.A. Vidy glagola v evenskom yazyke [Types of the Verb in the Even Language]. L.: Nauka, 1982. 113 p.

7. Robbek V.A. Grammaticheskie kategorii evenskogo glagola v funktsional'no-semanticheskom aspekte [Grammatical Categories of the Even Verb in the Functional-Semantic Aspect]. Novosibirsk: Nauka, 2007. $726 \mathrm{p}$.

8. Robbek V.A., Robbek M.E. Evensko-russkiy slovar' [The Even-Russian Dictionary]. Novosibirsk: Nauka, 2005. 353 p.

9. Sadovnikova I.I. Leksiko-semanticheskoe slovoobrazovanie kak sposob obogashcheniya evenskogo yazyka [Lexico-Semantic Word Formation as a Way of Enriching the Even language]. Aktual'nye voprosy sovremennogo yazykoznaniya. Novosibirsk 2012: 120-136. 
10. Tikhonov A.N. Slovoobrazovatel'nyy slovar' russkogo yazyka: v 2-kh $t$ [The Word Formation Dictionary of the Russian language: 2 Volumes]. M.: Russkiy yazyk, 1985. T. 1. 856 p. Tikhonov A.N. Slovoobrazovatel'nyy slovar' russkogo yazyka: v 2-kh t. M.: Russkiy yazyk, 1985. T. 2. $887 \mathrm{p}$.

11. Tsintsius V.I. Ocherk grammatiki evenskogo (lamutskogo) yazyka [Essay on the Grammar of the Even (Lamut) Language]. Ch.1. L.: Uchpedgiz, 1947. 269 p.

12. Wellmann H. Deutsche Wortbildung, Typen und Tendenzen in der Gegenwartsprache. Zweiter Hauptteil: Das Substantiv. Schwann, Düsseldorf, 1975. 500 p.

13. Dokulil M. Tvoreni slov v cestine. T. 1. Praha, 1962. 263 p.

14. Arnold I.V. The English Word. M.: BILL, 1986. 296 p.

15. Bloomfield L. Language. New York: Holt, 1965. 564 p.

\section{ДАННЫЕ ОБ АВТОРЕ}

Саввинова Степанида Николаевна, научный сотрудник, кандидат филологических наук Институт гуманитарных исследований и проблем малочисленных народов Севера СО РАН

ул. Петровского, 1, г. Якутск, 677027, Российская Федерация stepanidasavvinova@mail.ru

\section{DATA ABOUT THE AUTHOR}

Savvinova Stepanida Nikolaevna, $\mathrm{PhD}$ in Philology

The Institute for Humanities Research and Indigenous Studies of the Problems of the North Russian Academy of Sciences Siberian Branch

1, Petrovsky Str., Yakutsk, 677027, Russian Federation stepanidasavvinova@mail.ru

ORCID: 0000-0002-9026-1196 